\title{
Percutaneous Coronary Intervention for a Pregnant Woman with Acute ST Elevation Myocardial Infarction: A Case Report
}

\author{
Farouk Boukerche ${ }^{1,2}$, Adam Ahamat Ali ${ }^{3,4^{*}}$, Nadia Laredj ${ }^{1,2}$, Leila Hammou ${ }^{1,2}$ \\ ${ }^{1}$ Cardiology Department, Oran University Hospital Center, Oran, Algeria \\ ${ }^{2}$ Faculty of Medicine, Oran, Algeria \\ ${ }^{3}$ Cardiology Department, Renaissance University Hospital Center, N'Djamena, Chad \\ ${ }^{4}$ Faculty of Human Health Sciences of N'Djamena, N'Djamena, Chad \\ Email: boukerche.farouk@yahoo.fr, *aliadamahmat@hotmail.com,1dj_nadia@yahoo.fr, Leilahammou@yahoo.fr
}

How to cite this paper: Boukerche, F., Ali, A.A., Laredj, N. and Hammou, L. (2020) Percutaneous Coronary Intervention for a Pregnant Woman with Acute ST Elevation Myocardial Infarction: A Case Report. World Journal of Cardiovascular Diseases, 10, 357362.

https://doi.org/10.4236/wjcd.2020.106034

Received: May 13, 2020

Accepted: June 14, 2020

Published: June 17, 2020

Copyright (C) 2020 by author(s) and Scientific Research Publishing Inc. This work is licensed under the Creative Commons Attribution International License (CC BY 4.0).

http://creativecommons.org/licenses/by/4.0/

\begin{abstract}
Acute myocardial infarction in women during childbearing age is rare. We report a case of a 40-year-old female patient with no history or cardiovascular risk factors, 24-week pregnant who presented with acute coronary syndrome with an ST-elevation anterior extended complicated by cardiogenic shock. Cardiac ultrasound showed systolic dysfunction of the left ventricle at 30\%. Emergency coronary angiography revealed subocclusion of the proximal anterior interventricular artery. We performed a primary angioplasty with placement of a stent after balloon predilation with a satisfactory agiographic result and an improvement in the hemodynamic state. The patient gave birth by cesarean section at 30 weeks of pregnancy after a pocket rupture of infectious waters. The newborn died after 72 hours. After 6 years of evolution, the patient remained asymptomatic under medal treatment.
\end{abstract}

Keywords

Pregnancy, Acute Coronary Syndrome, Primary Angioplasty, Oran-Algeria

\section{Introduction}

Acute myocardial infarction in women during childbearing age is rare (1 per 36,000 births) [1] [2]. Pregnancy, however, has been shown to increase the risk of acute myocardial infarction 3 to 4 folds [1] [3] [4]. The importance of the thrombotic component is attached to the hypercoagulability of pregnancy. The coronaries are often angiographically normal in postpartum infarctions. Spontaneous coronary dissection appears to be a specific cause of infarction during 
pregnancy or postpartum. With the continuing trend of childbearing at older ages and advances in reproductive technology enabling many older women to conceive, it may be expected that its occurrence will increase [5]. During pregnancy, the diagnosis of myocardial infarction is often made late. Clinical manifestations are often atypical, occurring most often in patients with no known history of coronary artery disease [6]. The maternal mortality rate is high [7]. During the last decade, a major change has been witnessed in both the diagnostic and therapeutic approaches to patients with acute myocardial infarction, which has led to an improvement in the outcome. These changes may have affected pregnant patients as well. The purpose of this work is to highlight the severity of acute myocardial infarction in pregnant women.

\section{Observation}

Madame BH aged 40, mother of a living child and 24 weeks pregnant, consulted on December 31, 2013 in the cardiology emergency department of the Oran University Hospital Center for acute retrosternal pain radiating to the left arm which was evolving for 15 hours. She had no cardiological history or cardiovascular risk factors.

On the physical examination, the patient was dyspneic at rest with an altered state. Her clinical parameters were; $85 \%$ oxygen saturation, temperature at $36.5^{\circ} \mathrm{C}$, blood pressure at 75/40 $\mathrm{mmHg}$ and heart rate at 120 beats per minute. During cardiac auscultation, the heart rate was regular but there were crackling groans during pulmonary auscultation.

The electrocardiogram below showed a sinus tachycardia at 120 cycles per minute, necrosis and ST elevation in the extended anterior (Figure 1).

The cardiac ultrasound showed systolic dysfunction of the left ventricle at $30 \%$ with anterior, apical and lateral hypokinesia and an elevation of pulmonary arterial pressures.

Emergency coronary angiography revealed sub-occlusion of the proximal anterior interventricular artery (Figure 2). Then, we performed a primary angioplasty under aspirin and heparin with placement of a bare stent (BMS) $3 \times 18 \mathrm{~mm}$ after balloon predilation with a satisfactory agiographic result (Figure 3). During the procedure, the patient benefited from a double anti-platelet aggregation: aspirin $100 \mathrm{mg} /$ day and clopidogrel $75 \mathrm{mg} /$ day, furosemide $20 \mathrm{mg} /$ day, carvedilol $6.25 \mathrm{mg} / \mathrm{day}$, as well as anticoagulation with low molecular weight heparin. The standard biological blood tests were unremarkable. Except significant increase in troponins at $4000 \mathrm{ng} / \mathrm{l}$ and Brain Natriuretic Peptide at $2000 \mu \mathrm{g} / \mathrm{ml}$.

The evolution was rapidly clinically favorable with the disappearance of angina, the progressive disappearance of dyspnea and an improvement in systolic function of the left ventricle to $40 \%$.

On the obstetric level, the patient presented a threat of premature delivery with cracking of the amniotic sac on the day of her admission in an infectious context treated medically. A complete rupture of the amniotic sac while going 


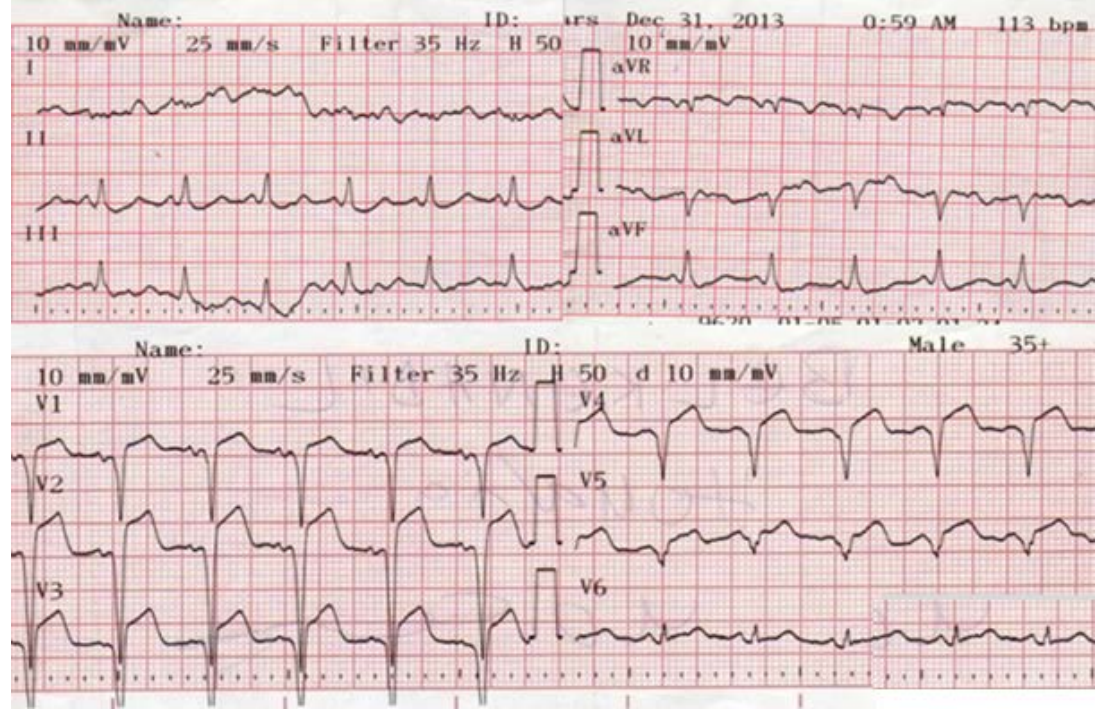

Figure 1. Electrocardiogram showing a sinus tachycardia at 120 cycles per minute, necrosis and ST elevation in the extended anterior.

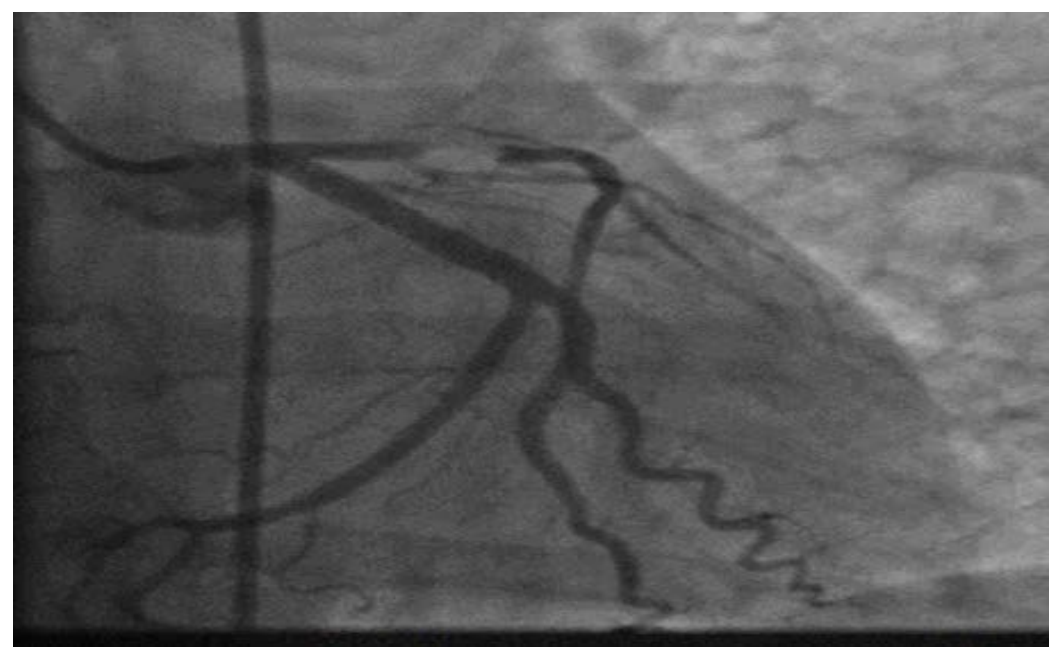

Figure 2. Coronary angiography showing sub-occlusion of proximal LAD with TIMI I flow.

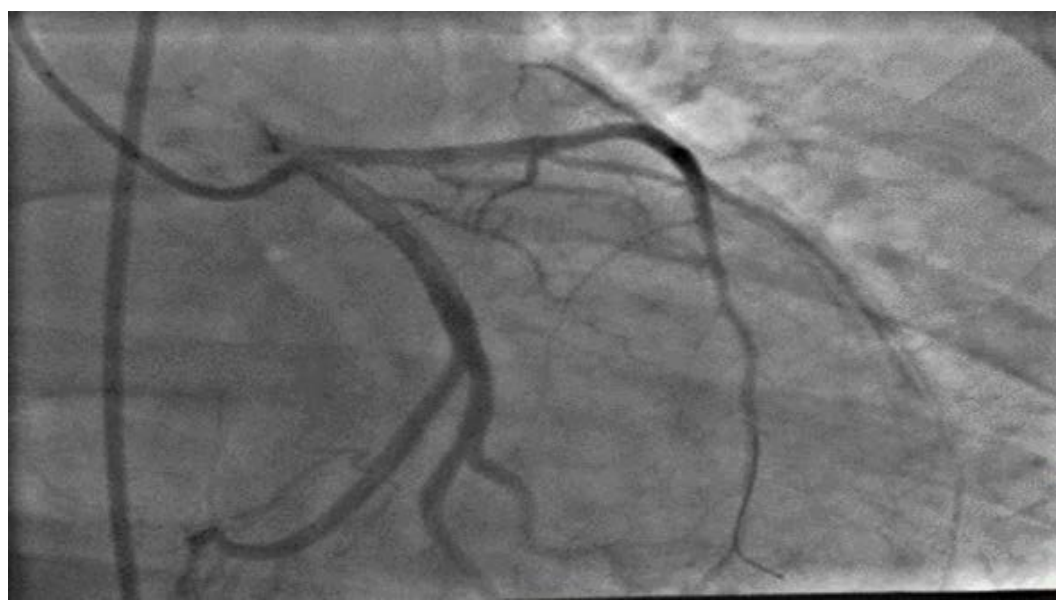

Figure 3. Post procedural angiography shows no residual stenosis (TIMI III flow). 
into labor at 30 weeks of pregnancy resulted in an obstetric decision to perform an early cesarean delivery with a temporary interruption of Clopidogrel for 3 days. A fetal pulmonary maturation was ensured by betamethasone. The patient gave birth to a girl weighing $1.25 \mathrm{~kg}$ and an Apgar score of 6/10 by caesarean section. The newborn was hospitalized in neonatology but unfortunately died after 72 hours of life. Postpartum monitoring was uneventful.

In July 2019 (6 years later), the patient was asymptomatic with a 45\% - 50\% left ventricular systolic ejection fraction on carvedilol $25 \mathrm{mg} /$ day, ramipril 10 $\mathrm{mg} /$ day, aspirin $100 \mathrm{mg} /$ day and atorvastatin $80 \mathrm{mg} / \mathrm{j}$.

\section{Discussion}

Myocardial infarction is a life-threatening condition which is rare during pregnancy. About half of myocardial infarctions occur before delivery, especially in the third trimester, and the other half during the postpartum period [1] [8]. The risk factors are maternal age, diabetes, hypertension or preeclampsia. The prevalence of coronary atherosclerosis is low in young women, however, it tends to increase with childbearing age and certain risk factors such as smoking and diabetes. Coronary atherosclerosis is only present in approximately half of the cases of myocardial infarction during pregnancy, the other half being in connection with a thrombotic occlusion without evidence of atherosclerosis, a spasm or a coronary dissection [8] [9]. In the review by Roth et al in 2008 [2], $40 \%$ of the women had coronary stenosis, $8 \%$ had a thrombus, $27 \%$ had coronary dissection, $2 \%$ had spasms and $13 \%$ of the arteries were normal.

Early diagnosis of acute myocardial infarction during pregnancy is often hindered by mistaking its signs and symptoms for normal manifestations of pregnancy and because of a low level of suspicion [6]. Similarly, as in the case of our patient who was presented in our cardiology department 15 hours after the onset of symptoms and partly explaining the severity of her clinical presentation. Diagnosis is confirmed as it is in nonpregnant patients [6], primarily by electrocardiogram and changes in enzyme levels. Echocardiography can be done safely during pregnancy to confirm the presence of ischemia by showing the transient, regional wall motion abnormality that corresponds to electrocardiographic changes.

Although the management of acute myocardial infarction and its complications should follow the usual principles of care, fetal considerations may affect the choice of therapy ( $\mathrm{X}$ ray, avoid statin and converting enzyme inhibitor). Full consultation with the attending obstetrician, cardiologist, and anaesthesiologist is essential to optimize maternal and fetal well-being.

Therapeutically, thrombolytics should be avoided during pregnancy even if the risk of maternal and fetal hemorrhage seems moderate [8] [10] [11]. Some reports have documented complications such as maternal hemorrhage, preterm delivery, fetal loss, spontaneous abortion, minor vaginal bleeding, massive subchorionic hematomas, abruptio placenta, uterine bleeding requiring emergency 
cesarean section, and post-partum hemorrhage requiring transfusion [12] [13]. Additionaly, if the mechanism of the infarction is a coronary dissection, the thrombolytics may worsen and increase the risk of bleeding leading to further dissection [14]. For these reasons, thrombolytics should be considered a second choice to primary Angioplasty in patients with ST-segment elevation acute myocardial infarction during pregnancy and especially during the peripartum and early postpartum periods when the incidence of coronary dissection is high [2] [3]. However, the use of radiation during pregnancy should be kept to a minimum [15]. For the rest of the therapies, the prescription is identical to that for nonpregnant women except for the angiotensin converting enzyme inhibitors, angiotensin-receptor antagonists and statins (proven teratogenic effect).

\section{Conclusion}

The occurrence of myocardial infarction in pregnant women is serious. Management should follow the usual principles of care for acute myocardial infarction. However, selection of diagnostic and therapeutic approaches may be greatly influenced by fetal safety.

\section{Conflicts of Interest}

The authors declare no conflicts of interest regarding the publication of this paper.

\section{References}

[1] Ladner, H.E., Danielsen, B. and Gilbert, W.M. (2005) Acute Myocardial Infarction in Pregnancy and the Puerperium: A Population-Based Study. Obstetrics \& Gynecology, 105, 480-484. https://doi.org/10.1097/01.AOG.0000151998.50852.31

[2] Roth, A. and Elkayam, U. (2008) Acute Myocardial Infarction Associated with Pregnancy. Journal of the American College of Cardiology, 52, 171-180.

https://doi.org/10.1016/j.jacc.2008.03.049

[3] James, A.H., Jamison, M.G., Biswas, M.S., et al. (2006) Acute Myocardial Infarction in Pregnancy: A United States Population-Based Study. Circulation, 113, 1564-1571. https://doi.org/10.1161/CIRCULATIONAHA.105.576751

[4] Badui, E. and Enciso, R. (1996) Acute Myocardial Infarction during Pregnancy and Puerperium: A Review. Angiology, 47, 739-756. https://doi.org/10.1177/000331979604700801

[5] Paulson, R.J., Boostanfar, R., Saadat, P., et al. (2002) Pregnancy in the Sixth Decade of Life: Obstetric Outcomes in Women of Advanced Reproductive Age. JAMA, 288, 2320-2323. https://doi.org/10.1001/jama.288.18.2320

[6] Bondagji, N.S. (2012) Ischaemic Heart Disease in Pregnancy. Journal of the Saudi Heart Association, 24, 89-97. https://doi.org/10.1016/j.jsha.2011.12.002

[7] El-Deeb, M., El-Menyar, A., et al. (2011) Acute Coronary Syndrome in Pregnant Women. Expert Review of Cardiovascular Therapy, 9, 505-515. https://doi.org/10.1586/erc.11.19

[8] Roth, A. and Elkayam, U. (1996) Acute Myocardial Infarction Associated with Pregnancy. Annals of Internal Medicine, 25, 751-762. https://doi.org/10.7326/0003-4819-125-9-199611010-00009 
[9] Iadanza, A., Del Pasqua, A., Barbati, R., et al. (2007) Acute ST Elevation Myocardial Infarction in Pregnancy Due to Coronary Vasospasm: A Case Report and Review of Literature. International Journal of Cardiology, 115, 81-85. https://doi.org/10.1016/j.ijcard.2006.01.016

[10] Leonhardt, G., Gaul, C., Nietsch, H.H., et al. (2006) Thromobolytic Therapy in Pregnancy. Journal of Thrombosis and Thrombolysis, 21, 271-276. https://doi.org/10.1007/s11239-006-5709-Z

[11] Turrentine, M., Braems, G. and Ramirez, M. (1995) Use of Thrombolytics for the Treatment of Thromboembolic Disease during Pregnancy. Obstetrical \& Gynecological Survey, 50, 534-541. https://doi.org/10.1097/00006254-199507000-00020

[12] Murugappan, A., Coplin, W.M., Al-Sadat, A.N., et al. (2006) Thrombolytic Therapy of Acute Ischemic Stroke during Pregnancy. Neurology, 66, 768-770. https://doi.org/10.1212/01.wnl.0000201272.90216.15

[13] Usta, I.M, Abdallah, M. and El-Hajj, M. (2004) Massive Subchorionic Hematomas Following Thrombolytic Therapy in Pregnancy. Obstetrics \& Gynecology, 103, 1079 1082. https://doi.org/10.1097/01.AOG.0000109210.93819.07

[14] Koul, A.K., Hollander, G., Moskovits, N., et al. (2001) Coronary Artery Dissection during Pregnancy and the Postpartum Period: Two Case Reports and Review of Literature. Catheterization and Cardiovascular Interventions, 52, 88-94. https://doi.org/10.1002/1522-726X(200101)52:1<88::AID-CCD1022>3.0.CO;2-P

[15] Ain, D.L., Narula, J. and Sengupta, P.P. (2012) Cardiovascular Imaging and Diagnostic Procedures in Pregnancy. Cardiology Clinics, 30, 331-341. https://doi.org/10.1016/j.ccl.2012.05.002 